\title{
Quantitative Analysis of E-commerce Application and Operation Performance in SMEs Based on Data Mining
}

\author{
Yan HaiBo ${ }^{1}$, Li Juan ${ }^{2}$ and Liu $\mathrm{Jie}^{3}$ \\ ${ }^{1}$ Academic Affairs Department, North China University of science and technology, \\ Tangshan, Hebei, China \\ ${ }^{2}$ YiSheng College, North China University of science and technology, Tangshan, \\ Hebei, China \\ ${ }^{3}$ Retire Work Department, North China University of science and technology, \\ Tangshan, Hebei, China \\ Email:ljtiti@126.com
}

\begin{abstract}
The development of information technology changes people's consumption patterns, more and more people are starting to accept online shopping, because E-commerce platform has the advantages of convenience, low price and security. In this paper, the author analyze how e-commerce application will effect on small and medium enterprises, by using the data mining method, result shows that e-commerce platform has significant performance in increasing customer and enhancing the brand awareness, more than $77.67 \%$ companies agree that application of e-commerce platform can immediately increase orders. The result of factor analysis shows that information quality and service quality is the key factors that will influence the network platform. Therefore, enterprises should strengthen the application of electronic commerce, at the same time; they should also pay attention to the quality of their own network platform.
\end{abstract}

Keywords: Data Mining, Electronic commerce, SMEs, information quality

\section{Introduction}

In 2015, China's e-commerce transactions exceeded 18 trillion, the B2B e-commerce transactions accounted for about 53.3\%. Electronic commerce is become one of the powerful weapon as small and medium-sized enterprise develop domestic and foreign markets and obtain sustainable competitive advantage, so research on SME e-commerce adoption has gradually become much popular topics and frontiers. Since the Davis (1985) proposed for individual level information technology acceptance model [1], domestic and foreign scholars in accepting a personal level information technology research in the field has achieved fruitful results, and has formed a mainstream paradigm. On the enterprise level information technology adoption research bit thin, although there have been some achievements. Technical, organizational, logical framework combined with Rogers's diffusion of innovation theory and expands. With the development of E-commerce and the small and medium-sized enterprises in economic and social development has been playing an increasingly important role [2]. More and more research began to focus on small and medium sized enterprises continue to adopt electronic commerce influence factors of this topic. Scholars agree that although the first adoption of the diffusion of ecommerce is very critical, but the continued use of electronic commerce will determine its long-term continuation and final success. B2B electronic commerce is one of the most important models for small and medium enterprises to develop e-commerce, so it is very important to study the influence factors of B2B e-commerce adoption. 
In recent years, small and medium enterprises rapid development of all countries in the world, contribution to the national economy and social development have become increasingly prominent showed amazing vigor and vitality, plays an important role in the economic development of all countries in the world, by the governments concerned and. Therefore, the issues related to the small and medium-sized enterprises are also more and more, its importance is also of concern [3]. In theory, small and medium-sized enterprises refer to the enterprises with low concentration of labor force, labor means or labor, or small scale of production and trading volume. Whether in developed countries or in developing countries, on the scale of the enterprise determine there is large, medium and small scale, but in the division of small and medium enterprise standards shall be using a principle of relativity, namely enterprise of region, industry and time of different division of the standard is different. At the same time, the qualitative and quantitative standards; Japan, Germany and Italy and other countries directly using quantitative criteria to determine the small and medium-sized enterprises [4-5]; promote the healthy development of small and medium-sized enterprises of our country guide to China's economic and social development make important contributions to, the small and medium-sized enterprises of the people's Republic of China to promote law concept of small and medium enterprises are defined as: established within the territory of the people's Republic of China in accordance with the law, that help to meet the social needs, increasing employment, in line with the national industrial policy, production scale is small various ownership and various forms of enterprise [6].

At the present stage of our country small and medium-sized enterprise electronic commerce related research although many, but scholars research direction and focus has not been focused, and basically is on small and medium enterprises carry out significance, value and mode of electronic commerce, which leads to small and medium-sized enterprise Electronic Commerce adopted the lack of deep understanding. In this study, according to the existing research dynamic, from the small and medium-sized enterprise electronic commerce adoption process analysis, through the process of analysis and mining factors affecting the adoption of e-commerce for SMEs, and combining with analysis of actual cases to demonstrate the role of these factors.

\section{Literature Review}

\subsection{E-commerce in SMEs}

Under the electronic commerce pattern, although competition theory does not change, but the rules are not the same, particularly worthy of attention is the variable cost of digital products and services become very low, and the competition including the competition between the old economy and new economy, competition force changes may very quickly [7]. Some scholar believes that competition in the network is more like a network of relationships, and unlike industrial economy level "command control" mode into its barrier is very low, and nature ecological system similar to, Internet economy business activities also its organization, according to the profits of the company and for customers to create value for natural selection. Chinese scholars pay more attention to the issues related to research on e-commerce development of small and medium-sized enterprises from the management perspective [8]. In terms of subject attribute, the electronic commerce belongs to the branch of industrial and commercial management disciplines, so scholars in our country choose from management perspective to study issues related to the development of small and medium-sized e-commerce. Current focus on small and medium-sized enterprise electronic commerce research mainly gathered in small and medium-sized enterprise electronic commerce development present situation and countermeasure analysis on the one hand, on the small and medium-sized enterprise electronic commerce development model, scholars from the perspective of transaction 
cost economics proposed three modes of electronic commerce development of small and medium-sized enterprises "market, independent research and development and organization mode.

1) Information service model: $B 2 B$ e-commerce in our country to the information service model as a starting point, the first to solve the problem of enterprise information asymmetry, the profit model is mainly charged with the form of membership fees. Since the establishment of Alibaba in 1999, there have been a large number of B2B e-commerce platforms to provide information services on the market. In terms of information services, each B2B e-commerce business gradually extended its own special services, becoming the core competitiveness of enterprise development.

2) Transaction service model: transaction process and online shopping process exactly the same can not only solve the problem of asymmetric information, but can also help customers achieve online transactions and information flow, logistics and capital flow of the three flow unity. At present, the foreign trade market, commodities and small wholesale areas appeared online trading services platform. This kind of platform profit model is in the form of charge commissions[9].

3) Resources integration modes: mode of resources integration means B2B Ecommerce development to the mature stage of the mainstream model. Such a platform can be for users provide a full range of electronic commerce solution and implementation of trade in every link of resource integration. In this model, core ecommerce enterprises to achieve docking with the banks, logistics companies and customs and institutions and ultimately achieve every aspect of e-commerce, which is $\mathrm{B} 2 \mathrm{~B}$ e-commerce in the future development of a trend.

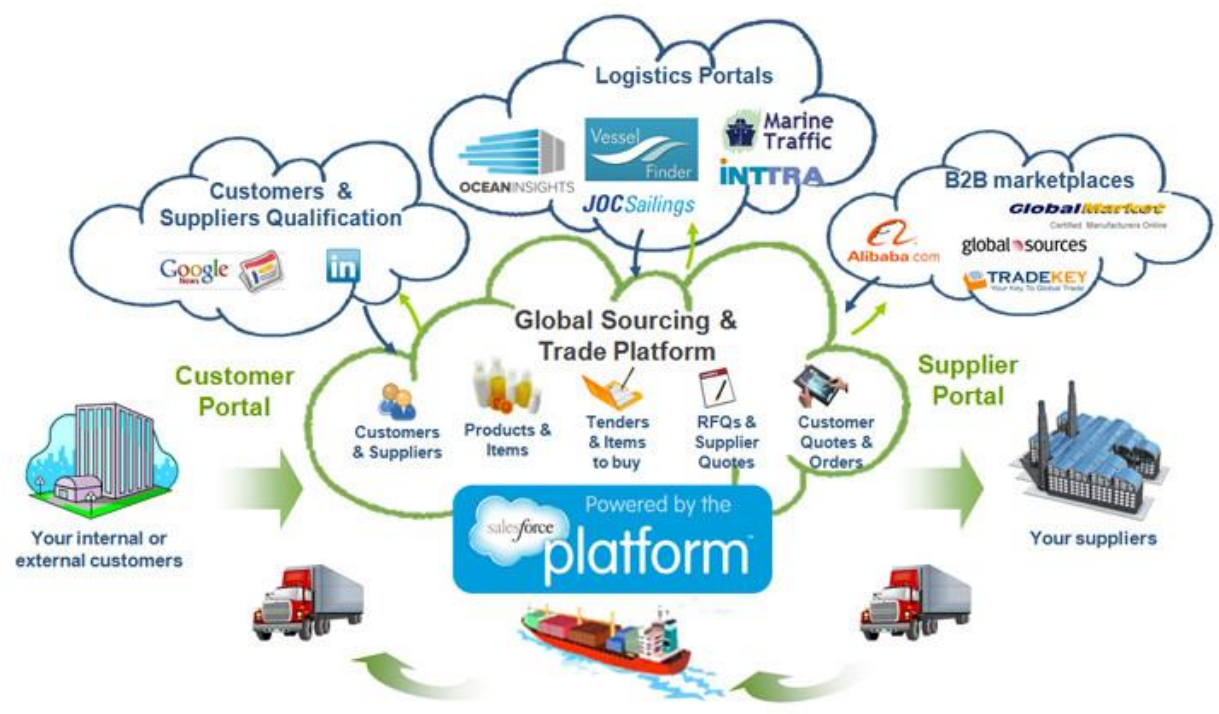

Figure 1. E-business Platform

\subsection{The Influence of E-Commerce on the Enterprise Competitiveness}

Although the development time is not long, but the use of the Internet in information exchange and resource sharing, cost savings, get information to the positive role, at present many of the world's small and medium-sized enterprises began to e-commerce as a weapon, expectations in the global competition to gain competitive advantage in competition, even some small and medium enterprises seize opportunity of e-commerce, has been the rapid growth of multinational company has caught the attention of the world, 
the effect of Electronic Commerce on the development of the small and medium-sized enterprise is very significant [10]. Electronic commerce can communicate with any Internet's place in the world, electronic commerce breaks through the limit of time and region, so that the small and medium-sized enterprises to break through the time and geographical constraints, to promote their own business, business all over the world. With application of e-commerce in small and medium-sized enterprises and large enterprises, the world as their target market, with large enterprises in an equal environment of competition. In such an equal competition, it reducing the small and medium-sized enterprises and large enterprises in the information disadvantage.

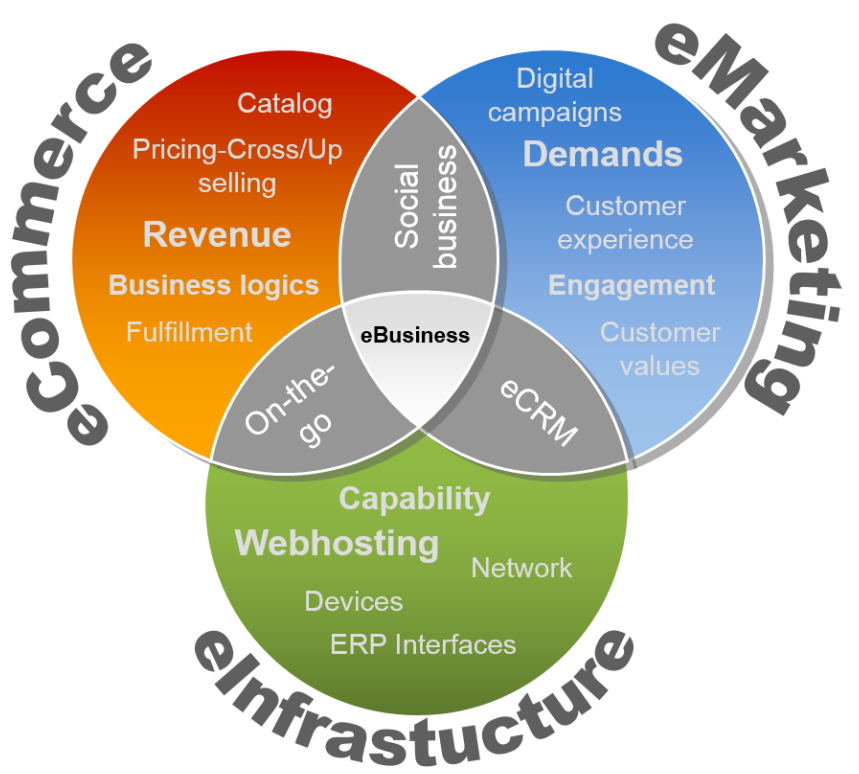

Figure 2. E-business Advantage

Mining of electronic commerce to promote global resources are incorporated into the network, small and medium-sized enterprises can with e-commerce breakthrough in time and geographical constraints, opportunities for small and medium-sized enterprises and large enterprises under equal conditions of competition to create a good condition. This not only changed the way of competition in the small and medium-sized enterprises, but also greatly expanded the field of competition. Because of the extensive application of electronic commerce, the international and domestic market expanded on the Internet has been greatly expanded, thus making the field of international and domestic competition unprecedented expansion [11-12]. E-business can break through the limitation of traditional trading space and time, the traditional transaction must have a fixed place, to have a middleman, use the traditional marketing mode and the traditional means of supervision, and electronic commerce directly in the online virtual market for, do not have a fixed place to support, directly with the buyer to contact, and through the network marketing, the marketing object expand, thus broadening the scope of the market of small and medium-sized enterprises, for small and medium-sized enterprises to obtain new business opportunities provides effective way.

\section{Model Design and Variable}

\subsection{Data Mining}

With the rapid development of Internet technology, the data on the Internet is growing rapidly. How to find useful information in the world's largest collection of data has 
become a hot topic in data mining research. Web data mining is based on the analysis of Shanghai Web volume data, using data mining algorithms effectively collect, choose and store the information of interest and found the relationship between the new concept and their growing information, realize the automation of information processing. Web data mining system based on cloud computing is a new knowledge and rule in the environment of massive data and computing resources on the Internet. Web data mining based on cloud computing is consistent with the basic process of traditional Web data mining, which can be divided into 3 stages: data preprocessing, data mining and pattern evaluation, but only in the way of data processing,

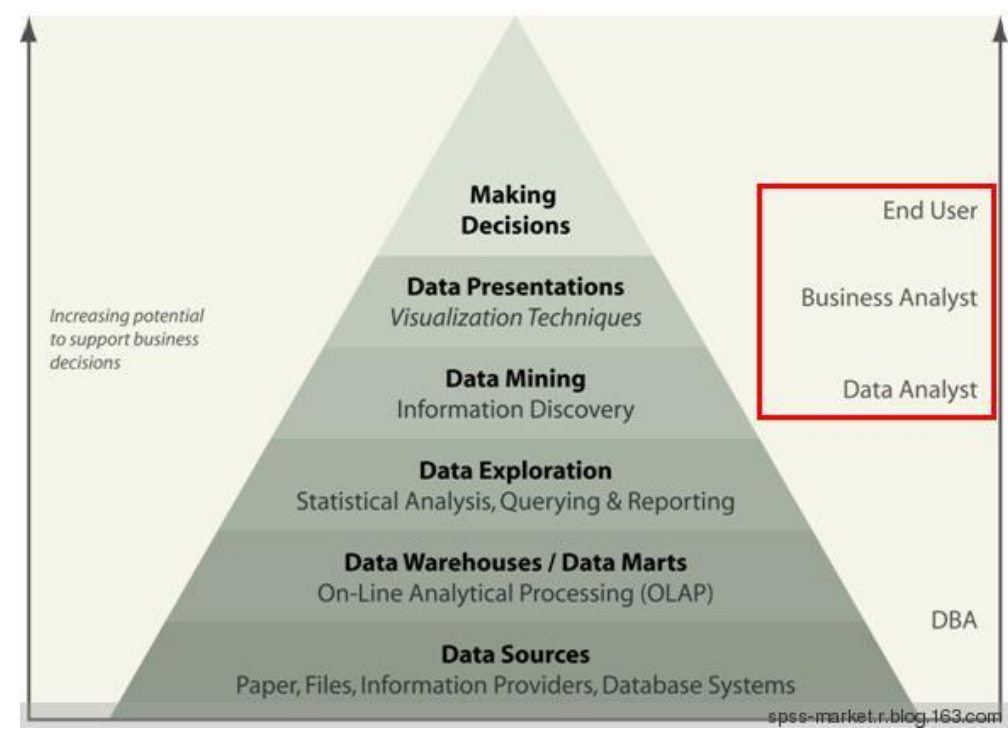

Figure 3. Data Mining Based on Cloud Computing

Compared with the traditional method, deep learning method driven by data, can automatically extract features from the data, for the analysis of large data, unstructured model is unknown changeable, cross domain has a significant advantage. At present, the depth of the neural network used in big data analysis is mainly the feed forward neural networks. Learning algorithm is the method of regulating the network weight, that is:

$$
w_{\text {new }}=w_{\text {old }}+\Delta w
$$

Then, target output error can express as:

$$
e_{k}(t)=\left\{\begin{array}{c}
d_{k}(t)-y_{k}(t) \quad k \in T(t) \\
0, \quad \text { otherwise }
\end{array}\right.
$$

The performance function of the network can be expressed as:

$$
J(t)=\frac{1}{2} \sum_{k=1}^{n}\left[e_{k}(t)\right]^{2}
$$

The total performance function of the network is:

$$
J\left(t_{o}, t_{1}\right)=\sum_{\tau=t_{0}+1}^{t_{1}} J(\tau)
$$

Conclusion using the chain rule:

$$
\frac{\partial J\left(t_{0}, t_{1}\right)}{\partial w_{i j}}=\sum_{k \in U} \frac{\partial J\left(t_{0}, t_{1}\right)}{\partial s_{k}(\tau)} \times \frac{\partial s_{k}(\tau)}{\partial w_{i j}(\tau)}
$$

Error as: 


$$
\delta_{k}(\tau)=\left\{\begin{array}{c}
f^{\prime}\left(s_{k}(\tau)\right) e_{k}(\tau), \tau=t_{1} \\
f^{\prime}\left(s_{k}(\tau)\right)\left(\sum_{j=1}^{n} w_{k j} \delta_{j}(\tau+1)+e_{k}(\tau)\right)
\end{array}\right.
$$

The gradient of the network performance function in the weight space is:

$$
\nabla_{w} J\left(t_{0}, t_{1}\right)=\sum_{\tau=t_{0}+1}^{t_{1}} \delta_{i}(\tau) y_{i}(\tau-1)
$$
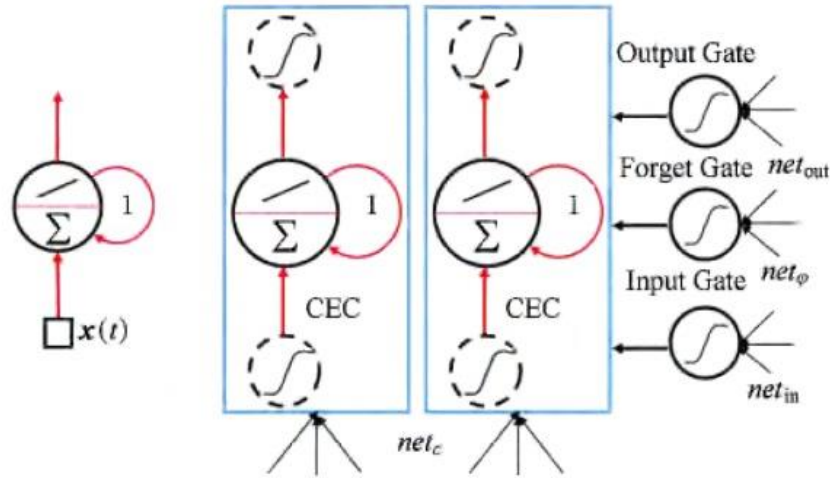

(a) A CEC of LSTM

(b) Architecture of memory block

Figure 4. Illustration of LSTM

\subsection{Model Design}

Sites for users, not just play the role of providing product information, but also may serve as a major responsibility for the service. User in the use of electronic commerce website, if contact website the feel good, can promote the users to make use of electronic commerce website for online shopping, which shows the site quality is one of the important factors that affect the behavior of the user. This section from the electronic commerce website should have the function of the transaction, the electronic commerce website quality dimensions for analysis and design. Any market transaction can be divided into three phases: the information gathering stage, the stage of the agreement and the completion of the transaction stage. In the information stage, the user collects information about the goods and services, looking for potential suppliers, consulting the price. If meet the needs of the user's initial, users will be to start the next stage; agreement stage, between suppliers and users negotiate, build a buyer seller relationship and through the contract to determine product specifications, payment methods and distribution channels and other details; in the completion of the transaction stage, in this stage of ordering the product delivery, including disclaimer of warranty and after-sales service and other issues. In the virtual environment of e-commerce sites, the interaction, that is, online communication becomes the issue of concern. We can find that explored from the perspective of information system of website quality dimensions with the electronic commerce website in the transaction process play of function is consistent. Therefore, this paper will from three dimensions: information quality, system quality and service quality to design electronic commerce website quality index

1) Comparison of quality information: when users make use of e-commerce shopping site, you first need to search commodity information, to more deeply understand the commodity and commodity, so e-commerce sites provide information relevance, accuracy and reliability will affect the user's behavior. Electronic commerce website in introduce goods not only the content is very 
detailed, real, but also provides a rich variety of goods, at the same time, accurate information classification can improve the search efficiency for users, information classification to consider the subject system but also conforms to the thinking habit of the user.

2) System quality: Although the content of the information provided by the website can meet the needs of users, but the design of the system will affect the content of the supply as well as the impact of the user's convenience. The interface design of the website system is friendly, is easy to operate, the overall design of the site is attractive and aesthetic effect, information organization is reasonable, online transaction process is convenient and quick, can let users accurate retrieval to the required commodity information, this will affect whether the user to continue to use the electronic commerce website. For personal information security and security of the site is also a factor of concern to the user. Provide intranet information navigation system can improve the efficiency of the user's query, due to each user's background knowledge and habits of different, they check the information retrieval entrance there are differences, the website needs according to user needs to provide as much as possible ways to retrieval.

3) Quality of service: to provide users with personalized customized services, can stimulate the needs of users. Different from ordinary enterprise website, ecommerce website can provide users with other users to exchange, as well as a platform for interaction with the business. Through e-commerce sites, users and businesses to achieve the degree of communication is greatly convenient, fast. Two-way interactive network, the user can direct dialogue with the business, the traditional one-way customer service into a two-way customer communication. At the same time, users use the network technology to achieve one to one, one to many, many to many interactive communication, greatly enhance the user's initiative and participation in the transaction. On the other hand, reflected in the communication between the users. The traditional personal opinion has a great influence on the consumer's consumption. Through a network of chat rooms, customers can communicate with people who need to know what they need, or who have had such experience, from which they can get a lot of advice, advice, and advice.

\subsection{Index Analysis}

Users choose when shopping online, unable to communicate face to face with the business, so the main use of electronic commerce website as a platform to communicate with the seller. Site characteristics directly affect the cognition and judgment of the business and the sale of product quality and provide quality of service, and become an important basis for consumers to decide whether to the shopping website. Since 1996, the quality of domestic and foreign scholars put forward many different standards to evaluate the electronic commerce website, to help enterprises to improve the quality of website construction. For example Kubly think should be from the following five criteria to evaluate the site quality: accurate, authoritative, objective, timely and comprehensive; XX using Microsoft usability guidelines given index, from the perspective of content, ease of use, promotion, customized service and affective factors of the five indicators, to the ecommerce website usability evaluation. Gomez has developed 5 level class indicators: ease of use, user confidence, site resources, customer relationship services and total cost. Bizrate to develop e-commerce website evaluation index is 10: patronize again website, ordering convenience, product selection, product information, product price, website of the appearance and performance, goods transport and handling, delivery on time, product line, customer support, order tracking.

For e-commerce website quality research, as proposed the framework of the analysis of the website, and to analyze and classify the web site. We think a website can be divided 
into two main parts: website content and website design. Website content mainly refers to the website includes a variety of information, trade and entertainment; website design is refers to a web site to how to present to the user, and web site using the interface to how information convenient for the user. We use a lot of subjective and objective measure to validate this framework; the results confirmed the correctness of this framework. The website can be simply to website content and website design classification, according to the two most, he suggested that future web designers in design and erection of the website, we can infer the framework of thinking. According to the electronic commerce website should have the function of each dimension, designed 20 indexes are shown in Table 1 of the electronic commerce website quality.

Table 1. Measurement Index of E-Commerce Website Quality

\begin{tabular}{|c|c|l|}
\hline Variable & entry & \\
\hline \multirow{5}{*}{} & IQ1 & Web site provides rich, detailed product information \\
\cline { 2 - 3 } & IQ2 & Multimedia display of commodity information \\
\cline { 2 - 3 } & IQ3 & The information can be updated timely \\
\cline { 2 - 3 } & IQ4 & Website provides accurate and reliable information \\
\cline { 2 - 3 } & IQ5 & Personal information protection statement \\
\cline { 2 - 3 } & IQ6 & Classification of commodity categories is clear \\
\cline { 2 - 3 } & DQ1 & Web site has a friendly user interface \\
\cline { 2 - 3 } & DQ2 & Overall design of the site beautiful \\
\cline { 2 - 3 } & DQ3 & Have good information navigation function \\
\cline { 2 - 3 } & DQ4 & Website can ensure the security of user information \\
\cline { 2 - 3 } & SQ1 & Web site to provide personalized custom services \\
\cline { 2 - 3 } & SQ2 & Web site has fast response time \\
\cline { 2 - 3 } & SQ3 & Site provides free space for the exchange of other customers \\
\cline { 2 - 3 } & SQ4 & Website provides interactive communication \\
\hline
\end{tabular}

\section{Empirical Analysis}

\subsection{Questionnaire Survey}

The survey used a survey questionnaire issued for the Taobao merchant's access an online survey of 384 questionnaires, 298 valid questionnaires, questionnaire recovery rate was $77.6 \%$. Uses questionnaire Likert 5 scale, from "very important", "important", "general", "not important" to "no use" were given 5, 4, 3, 2 and 1 points users, please according to their own subjective feelings for scoring, thus of variables were measured. According to the survey data show that the surveyed enterprises concerns of the industry Web site is in turn the practicality of the platform (can immediately for the enterprise to bring order), famous platform, platform operation difficulty degree, member companies data authenticity and legitimacy, platform service fee, website of trade information, and industry related degree, website reputation. This shows that the competitiveness of the industry Web site will show a diversified situation, degree of practicality, visibility and difficulty of operation, the use of price, trade information, word of mouth, and industry relevance, visibility and other factors are important influence factors of a industry site enterprises to use, especially $15.33 \%$ by research firm that the primary factors are associated with their industry, and detailed information, refer to Table 2. 


\section{Table 2. Factors Influencing the Choice of E-Commerce Website}

\begin{tabular}{|l|c|}
\hline \multicolumn{1}{|c|}{ Factor } & percentage \\
\hline Platform can immediately bring orders & 77.15 \\
\hline Platform visibility & 63.24 \\
\hline Platform operation difficulty & 60.12 \\
\hline The authenticity and legitimacy of the platform & 22.89 \\
\hline The price charged & 21.42 \\
\hline Trade information website & 16.15 \\
\hline
\end{tabular}

Adoption of B2B e-commerce many aspects have significant performance and 59.33\% of enterprises said electronic commerce to their enterprises bring new customers and $51.67 \%$ of enterprises said enterprise sales growth, $49.67 \%$ of enterprises said regional sales has been extended, $46.00 \%$ of enterprises said brand promotion, $46.67 \%$ of enterprises said e-commerce to reduce the cost of enterprise marketing, $35.00 \%$ of enterprises said reduce business operating costs, and $27.67 \%$ of the enterprises said they enterprises begin to pay more attention to the integrity of the enterprise and other enterprise survey said. Therefore, to promote the sales volume, reduce costs and expand the regional market is after the adoption of small and medium-sized enterprise ecommerce the main three direct effects. For details, please see Table 3.

\section{Table 3. The Significant Performance of Electronic Business}

\begin{tabular}{|l|c|}
\hline performance of E-commerce & percentage \\
\hline Increase customer & 59.24 \\
\hline Sales growth & 51.58 \\
\hline Expand the sales area & 48.42 \\
\hline Brand has been upgraded & 45.37 \\
\hline Reduce marketing costs & 42.26 \\
\hline Reduce operating costs & 34.18 \\
\hline
\end{tabular}

\subsection{Reliability Analysis}

This study uses SPSS software to calculate the mean and standard deviation of each evaluation index, and the results are shown in Table 4. Reliability analysis is to verify the reliability of the measurement indicators. Reliability refers to the level of consistency of the same measuring tool used by different investigators to reflect the degree of approximation of the results of repeated measurements under the same conditions. Reliability can be achieved by testing the internal consistency of the measurement tool. In this study, the Cronbach's $\alpha$ coefficient to measure the reliability of the questionnaire survey, in the process of reliability analysis, through SPSS13.0 operation for the variables in the questionnaire of the Cronbach's $\alpha$ coefficient, as shown in Table 4 shows can see, all the variables and the questionnaire of the consistency coefficient are greater than 0.5, indicating that the questionnaire is reliable. 
Table 4. The Reliability Analysis

\begin{tabular}{|c|c|c|c|c|c|}
\hline variable & Measurement & $\begin{array}{l}\text { mean } \\
\text { value }\end{array}$ & S.D. & $\begin{array}{c}\text { Cronbach's a if } \\
\text { item deleted }\end{array}$ & Cronbach's a \\
\hline \multirow{6}{*}{$\begin{array}{l}\text { Information } \\
\text { Quality } \\
\text { (IQ) }\end{array}$} & IQ1 & 3.45 & .868 & .858 & \multirow{6}{*}{0.874} \\
\hline & IQ2 & 3.02 & .827 & .884 & \\
\hline & IQ3 & 3.14 & .915 & .858 & \\
\hline & IQ4 & 3.38 & .857 & .876 & \\
\hline & IQ5 & 3.24 & .868 & .874 & \\
\hline & IQ6 & 3.18 & .758 & .862 & \\
\hline \multirow{4}{*}{$\begin{array}{c}\text { Web } \\
\text { Design } \\
\text { Quality } \\
\text { (DQ) }\end{array}$} & DQ1 & 2.89 & .764 & .845 & \multirow{4}{*}{0.868} \\
\hline & DQ2 & 3.12 & .775 & .848 & \\
\hline & DQ3 & 3.08 & .848 & .836 & \\
\hline & DQ4 & 3.11 & .844 & .840 & \\
\hline \multirow{4}{*}{$\begin{array}{c}\text { Service } \\
\text { quality } \\
\text { (SQ) }\end{array}$} & SQ1 & 3.16 & .758 & .811 & \multirow{4}{*}{0.824} \\
\hline & SQ2 & 3.08 & .819 & .786 & \\
\hline & SQ3 & 3.06 & .836 & .772 & \\
\hline & SQ4 & 3.16 & .757 & .813 & \\
\hline
\end{tabular}

\subsection{Exploratory Factor Analysis}

Before doing the factor analysis, the KMO value is used to analyze the data of the sample. The greater the value of KMO, the more common factor between the variables, the more suitable for factor analysis, according to Kaiser's point of view, how to KMO value is less than 0.5 , it is not suitable for factor analysis. Therefore, this study uses SPSS to explore the factor analysis, using the principal component analysis as a method of extracting factors, and using the variance of the maximum method of orthogonal rotation, get the factor structure. As can be seen from Table 5, the KMO value of the sample is $0.918>0.5$, which indicates that it is suitable for factor analysis. The chi square value of Bartlett ball test is 3753.241 , the significance level is 0, which indicates that the indexes are not opposite, but interrelated, and can carry on the factor analysis to the sample data. The principal component method to extract the eigenvalues greater than 1 information quality, system quality and service quality, three factors, as shown in Table 4, with questionnaire survey expected the same, the cumulative $65.40 \%$ explained variance, each item on its associated variable load factor is greater than 0.5 , the factor loadings of the variable cross not more than 0.5 , indicating that the questionnaire has good construct validity.

Table 5. The Result of KMO Statistical Test

\begin{tabular}{|c|c|c|}
\hline \multicolumn{2}{|c|}{ Kaiser-Meyer-Olkin } & .918 \\
\hline \multirow{3}{*}{ Bartlett test } & Approximate chi-square & 3753.241 \\
\cline { 2 - 3 } & Df & 120 \\
\cline { 2 - 3 } & Sig. & .000 \\
\hline
\end{tabular}

\subsection{Confirmatory Factor Analysis}

In this paper, we use confirmatory factor analysis of the sample data, and the parameter estimation method is the maximum likelihood method. Which is the factor load of the observation variable, which is the measurement error, the AVE value is greater than 0.5 , indicating the structure variables have good convergent validity, said more than $50 \%$ variance of the observed variables are explained. Using these three standards to evaluate the convergent validity of the questionnaire, the results are shown in Table 6. All 
indicators of the load factor is greater than 0.5 , according to the load factor and the corresponding measurement error can be calculated by combination of reliability and average variation extraction amount. According to as shown in Table 7, the factor of composite reliability is greater than 0.7 , average variance extracted volume were greater than 0.5, can draw the e-commerce website quality of each measurement indicators converge to the corresponding dimension. Therefore, the investigation of questionnaire design has convergent validity. From Table 8 the fitting optimization index can be seen, the fitting effect of website quality dimensions of the proposed model is good

Table 6. Exploratory Factor of Website Quality

\begin{tabular}{|c|c|c|c|c|}
\hline Index & Information Quality & web design quality & Service quality & eigenvalue \\
\hline IQ1 & .776 & .242 & .202 & \multirow{6}{*}{$\begin{array}{c}7.238 \\
(24.263 \%)\end{array}$} \\
\hline IQ2 & .764 & .160 & .121 & \\
\hline IQ3 & .683 & .323 & .320 & \\
\hline IQ4 & .780 & .179 & .186 & \\
\hline IQ5 & .759 & .135 & .244 & \\
\hline IQ6 & .752 & .338 & .094 & \\
\hline DQ1 & .315 & .747 & .168 & \multirow{4}{*}{$\begin{array}{c}1.701 \\
(21.294 \%)\end{array}$} \\
\hline DQ2 & .223 & .727 & .180 & \\
\hline DQ3 & .208 & .758 & .273 & \\
\hline DQ4 & .219 & .828 & .076 & \\
\hline SQ1 & .246 & .270 & .659 & \multirow{4}{*}{$\begin{array}{c}1.525 \\
(19.842 \%)\end{array}$} \\
\hline SQ2 & .259 & .060 & .776 & \\
\hline SQ3 & .049 & .176 & .699 & \\
\hline SQ4 & .226 & .138 & .762 & \\
\hline
\end{tabular}

Table 7. Combined Reliability and Average Variation of Website Quality

\begin{tabular}{|c|c|c|c|}
\hline Factor & $\begin{array}{c}\text { Information Quality } \\
\text { (IQ) }\end{array}$ & $\begin{array}{c}\text { web design } \\
\text { quality (DQ) }\end{array}$ & $\begin{array}{c}\text { Service quality } \\
\text { (SQ) }\end{array}$ \\
\hline Combined reliability (CR) & 0.89 & 0.88 & 0.84 \\
\hline $\begin{array}{c}\text { Average variation } \\
\text { extraction (AVE) }\end{array}$ & 0.77 & 0.77 & 0.67 \\
\hline
\end{tabular}

Table 8. Goodness of Fit

\begin{tabular}{|c|c|c|c|c|c|c|c|}
\hline index & X2/df & SRMR & RMSEA & GFI & CFI & NFI & NNFI \\
\hline Index value & 1.310 & 0.049 & 0.046 & 0.899 & 0.990 & 0.959 & 0.988 \\
\hline
\end{tabular}

Through the above empirical research, we can draw the conclusion that, for ecommerce website quality evaluation can be carried out from the three dimensions of information quality, system quality and service quality, and to simplify the e-commerce website quality evaluation standard. In the evaluation of specific e-commerce sites, it is possible to use confirmatory factor analysis results, depending on the three dimensions of information quality, system quality and service quality for first grade indexes, 14 measurement items as second grade indexes, factor loadings were normalized after treatment as the weight of evaluation indexes at all levels, provides a theoretical guidance for determining the actual evaluation weights. 


\section{Conclusion}

With the continuous advancement of information technology of the network and information resources development and utilization and development of electronic commerce, as the network economy era as a mainstream business approach, bringing the transformation of traditional enterprise management environment and the mode of economic trade, greatly impact on the enterprise's production operation, and management. As an important part of our national economy, small and medium-sized enterprises in the economic life in China play an important role. Small and medium-sized enterprise operators in the understanding to the electronic commerce lag is the main obstacle to influence the development of small and medium-sized enterprises e-commerce. Improve the operators of small and medium enterprises of electronic commerce cognition degree. The small and medium-sized enterprise should not regard the electronic commerce as the mystical high technology, also cannot regard it as the pure technical solution. Small and medium enterprises must realize that through e-commerce can establish their own image, show their products, expand the visibility of the enterprise, and thus more effective in looking for new trading partners, expand the market commanding heights. Also to realize electronic commerce is a kind of application that the small and medium-sized enterprises, suppliers, customers and partners through the Internet combined with a comprehensive, electronic commerce includes not only services business and online transactions, is also related to the "supply" to "need" of small and medium-sized enterprises of the ring Festival. At the same time, we must also realize that the small and medium-sized enterprise development electronic commerce, the sooner the better, it depends on the needs of small and medium-sized enterprises, employee quality, the investment ability of many factors, we cannot wait for who hesitates is lost; it cannot be so anxious, blind investment. Secondly, the expansion of publicity, enhance the awareness of small and medium enterprises to e-commerce. Small and medium-sized business operators to the understanding of electronic commerce determine the SME development of e-commerce and the application of e-commerce. In the process of small and medium-sized enterprise management, the operators of small and medium enterprises are often the makers of management decisions, so it is necessary to strengthen the knowledge and understanding of the use of electronic commerce

\section{References}

[1] H. Gebauer, M. Paiola, and B. Edvardsson, "A capability perspective on service business development in small and medium-sized suppliers", Scandinavian Journal of Management, vol. 28, no. 4, (2012), pp. 321-339.

[2] K. Grant and D. Edgar, "Risky business: Perceptions of e-business risk by UK small and medium sized enterprises (SMEs)", International Journal of Information Management, vol. 34, no. 2, (2014), pp. 99122.

[3] M. Shoki, L. Yun, and N. Zakuan, "Examining Dimensions of Electronic Service Quality for Internet Banking Services", Procedia - Social and Behavioral Sciences, vol. 65, (2012), pp. 854-859.

[4] S. Deniss, "Impact of e-environment on SMEs Business Development", Procedia - Social and Behavioral Sciences, vol. 156, (2014), pp. 409-413.

[5] M. Savrul, "The Potential of E-commerce for SMEs in a Globalizing Business Environment", Procedia Social and Behavioral Sciences, vol. 150, (2014), pp. 35-45.

[6] S. Djelassi, and I. Decoopman, "Customers' participation in product development through crowd sourcing: Issues and implications", Industrial Marketing Management, vol. 42, no. 5, (2013), pp. 683692.

[7] A. D. Zaridis and T. Dimosthenis, "Entrepreneurship and SME's Organizational Structure. Elements of a Successful Business", Procedia - Social and Behavioral Sciences, vol. 148, (2014), pp. 463-467.

[8] E. H. Sinem, and Z. Kabaday1, "Innovation Orientation, Market Orientation and e-Loyalty: Evidence from Turkish e-Commerce Customers", Procedia - Social and Behavioral Sciences, vol. 99, (2013), pp. 509-516.

[9] S. Manjit, and V. Kristine, "Social Commerce: A Contingency Framework for Assessing Marketing Potential", Journal of Interactive Marketing, vol. 27, (2013), pp. 311-323. 
[10] S. Samiee, "Global marketing effectiveness via alliances and electronic commerce in business-tobusiness markets", Industrial Marketing Management, vol. 37, no. 1, (2008), pp. 3-8.

[11] I. Janita and W. Chong, "Barriers of B2B e-Business Adoption in Indonesian SMEs: A Literature Analysis", Procedia Computer Science, vol. 17, (2013), pp. 571-578.

[12] S. Mohamad and U. Ahmad, "The Attributes of Electronic Service Quality (e-SQ) among Academic Librarians", Procedia - Social and Behavioral Sciences, vol. 65, (2012), pp. 260-265.

\section{Authors}
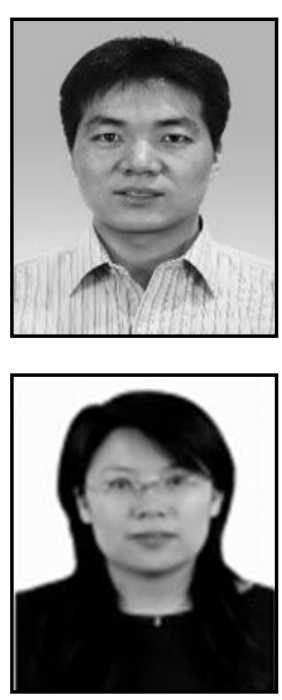

Yan HaiBo, He received his master degree in Educational Technology (2006) from Hebei University. Now he is a lecturer of North China University of Science and Technology. His current scientific interests include Education and Teaching management. $\mathrm{He}$ published more than 4 papers and two compositions.

Li Juan, She received her master degree in Management (2006) and PhD in Public Management (2015) from Tianjin University. Now she is full researcher in the School of Yisheng College at North China University of Science and Technology. Her current research interests include Public cultural services and Social management.

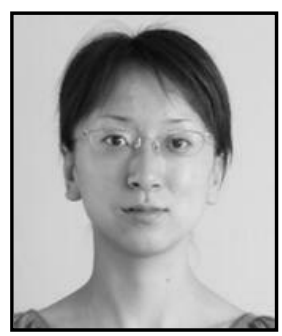

Liu Jie, She received her master degree in Chemical engineering from North China University of Science and Technology. Now she is full researcher in North China University of Science and Technology. She has completed more than three scientific research projects. Her current research interests include Social Management and Social Sciences. 
International Journal of Database Theory and Application Vol.9, No.11 (2016) 